\title{
De la vela al vapor, del vapor al motor. Las transiciones en la propulsión de la navegación ultramarina en Argentina (1921-1966) ${ }^{1}$
}

\author{
From the sail to the steam, from the steam to the engine. \\ Transitions in the propulsion of ultramarine navigation in Argentina (1921-1966)
}

\begin{abstract}
José ANTONio Mateo*
"Doctor en Historia por la Univesitat Pompeu Fabra de Barcelona. Investigador del Consejo Nacional de Investigaciones Científicas y Tecnológicas (CONICET, Argentina) y profesor de Historia Social Argentina de la Facultad de Ciencias Económicas de la Universidad Nacional de Entre Ríos.

$\measuredangle$ amateo@fceco.uner.edu.ar
\end{abstract}

\section{RESUMEN}

La navegación ultramarina ha sido el mecanismo que permitió la conformación de un mercado mundial ecuménico. Desde las flotas de galeones del período colonial en las américas, hasta la difusión del vapor y la hegemonía del motor a explosión luego, ningún sistema de transporte ha logrado desplazar a la navegación de su posición dominante. La navegación se ha perfeccionado hasta niveles increíbles e incrementado hasta superar la cifra de 100.000 buque mercantes inmensos circunnavegando el mundo. En el presente trabajo analizamos las dos transiciones más recientes en los modos de propulsión, es decir de la vela al vapor y de éste al motor a explosión, a partir de la presencia de buques en los puertos de Argentina; país que ha sido históricamente dependiente de la navegación en su comercio exterior. Las fuentes de información utilizadas se integran con textos especializados, estadísticas nacionales publicadas y una serie construida para Puerto Quequén, un importante puerto cerealero de Argentina. Se han podido verificar tanto los inicios como el final de las transiciones, más lentas que lo supuesto, y los períodos de convivencia de diferentes sistemas de propulsión.

PALABRAS CLAVE: navegación, vapores, motores, Argentina.

\section{ABSTRACT}

Ultramarine navigation has been the mechanism that allowed the conformation of an ecumenical world market. From the fleets of galleons of the colonial period in the Americas

1 El presente trabajo fue realizado con el apoyo de la Universidad Nacional de Entre Ríos (PID de la UNER N4065, Resolución CD 80/2017 y Resolución Consejo Superior UNER 2040/2017) para el proyecto titulado "Las políticas públicas y el transporte hidroviario en las terminales portuarias entrerrianas desde 1947 al presente" 
to the diffusion of steam and the hegemony of the engine to explosion then, no transport system has managed to displace the navigation of its dominant position. Navigation has been perfected to incredible levels and increased to surpass the figure of 100,000 merchant ship immense circumnavigating the world. In this paper we analyzed the two most recent transitions in the modes of propulsion, of the sail to the steam and of this to the engine to explosion, starting from the presence of ships in the ports of Argentina; country that has historically been dependent on navigation in its foreign trade. The sources of information used are integrated with specialized texts, published national statistics and a series built for Puerto Quequén, an important grain port in Argentina. It has been possible to verify both the beginnings and the end of the transitions, slower than what is supposed, and the periods of coexistence of different propulsion systems.

KEY WORDS: navigation, vapors, engines, Argentina.

“El 90\% del comercio mundial viaja por el agua. La vasta mayoría de la población mundial vive a pocos cientos de kilómetros de una costa. Cerca de tres cuartas partes del planeta están cubiertas por agua." (USCG-United States Coast Guard, 2009, p. 2)

\section{INTRODUCCIÓN}

Como afirma el epígrafe de la Guardia Costera de los Estados Unidos de América el comercio mundial sigue siendo totalmente dependiente de la navegación -y agregamos del petróleo como combustible-, a pesar de los avances logrados desde hace varias décadas tanto en el transporte carretero como ferroviario y en la aeronavegación. Si algo permitió la conformación de una "economía mundo" fue la navegación ultramarina. En un largo proceso la vela reemplazó al remo, el vapor a la vela y el motor a explosión a todos sus antecesores. Sin embargo, los sistemas convivieron un tiempo hasta que un sistema más avanzado se impusiera sobre el anterior. La literatura acerca del paso de la navegación a vela a la de vapor ha sido abundante. Desde un trabajo pionero de Frank Bowen, (1930), se han explorado aristas como su impacto en la inmigración (Cohn, 2005), lo que significó para los armadores y la familias de navegantes (Giménez i Blasco, 2009) y seguramente muchas otras. No obstante, no ha sido tanto así la que se ocupa de la transición del vapor al motor. Este instrumento ha permitido sin embargo nada menos que sumar otras nuevas tectologías, como el cada vez más hegemónico conteiner, incrementar la capacidad de bodega de los buques graneleros, potenciar el intercambio marítimo reduciendo el tiempo de las singladuras y de estadía en puerto, la reducción progresiva de las tripulaciones y un gran etcétera. En el presente trabajo analizamos las transiciones de la vela al vapor y del vapor al motor a partir de la presencia de buques en los puertos de Argentina, cuyo desarrollo ha sido y es inmensamente dependiente de este sistema de transportes. De manera más general, abordamos la transición de la vela 
al vapor en función de fuentes oficiales publicadas, y la del vapor al motor a través de una serie contínua elaborada sobre los registros de un puerto cerealero, el puerto de Quequén (ver Figura 1), sobre el océano atlántico argentino. Proponemos abordar las características de esta transición en función del número de navíos, el porte de las embarcaciones, las banderas, las rutas y los tripulantes que estos buques incorporaron.

\section{Las fuentes utilizadas}

Las fuentes editas utilizadas corresponden a una serie de textos clásicos sobre la historia de la navegación y técnicos de los cuales hemos extraído una serie de nombres de ingenieros y empresas que participaron en la evolución del transporte naval cuyos aportes hemos ampliado en algunos casos con ayuda de la Encyclopoedia Britannica.

Un segundo conjunto de fuentes lo componen los datos registrados por los censos adicionales que se realizaron juntamente con los tres primeros censos nacionales de población en Argentina (1869, 1895 y 1914), con los cuales se puede llegar a una idea bastante acabada de la transición de la vela al vapor mediante la presencia de esos tipos de embarcaciones en los puertos argentinos en el día del censo.

Finalmente, para la transición del vapor al motor a explosión hemos utilizado una serie con los registros de la autoridad portuaria de Puerto Quequén, en el frente atlántico de la provincia de Buenos Aires, cuyo rango de información contiene la fecha de arribo y zarpado, nombre de la embarcación, arboladura (motor, vapor o vela), origen y destino de las embarcaciones, cantidad de tripulantes y en algunas ocasiones cantidad y tipo de carga. Esta fuente, que se extiende desde 1914 hasta el presente (por más que se lleva el registro electrónico de esa información), pudo ser completada en algunos de sus huecos con un libro similar de la Aduana de Puerto Quequén que cubre el período analizado. Hemos intentado rastrear este tipo de fuentes para otros puertos, pero la búsqueda ha sido infructuosa al menos en su continuidad.

\section{La primera transición}

Desde su primera aparición registrada en el río Nilo, la navegación a vela dominó las singladuras durante milenios. Su remplazante, el buque impulsado por vapor, apenas lo hizo por 70 años. La utilización de esta tecnología, sumada a los cascos metálicos que llegaron a dimensiones que la madera no podía alcanzar; y a la hélice, como elemento propulsor que reemplazó a las ruedas laterales o traseras (y que podemos ver evocadas en la filmografía del río Mississippi), cambió para siempre la navegación de ultramar y los intercambios de personas y bienes en la economía mundo.

Sin embargo, los importantes avances en esta materia que implicaron progresivos aumentos de la velocidad, disminución del consumo de combustible (el carbón de coque) 
y mayores capacidades de bodega y carga -con la incorporación del frigorífico a bordo, por ejemplo-; y la posibilidad de navegación sin depender ya de los vientos, comenzarían a ser opacados progresivamente por el desarrollo de los motores a explosión y al uso de otro combustible fósil: el petróleo y derivados como el fuel oíl, el diésel oíl y el gasoil.

La navegación a vela, cuyos avances tecnológicos permitieron intercambios comerciales ecuménicos, tuvo poderosos avances en su arquitectura naval desde las primitivas velas cuadradas hasta los muy modernos clíperes de finales del siglo XIX. Sin embargo, la tecnología naval no evitaba que las embarcaciones estuvieran a merced de los vientos y de las condiciones del mar, así como de la pericia de la tripulación para sacarle jugo a la menor brisa. Además, con interminables jornadas de trabajo, eran muy difíciles las condiciones de vida a bordo, en viajes casi siempre de duración indeterminada. Las conocidas imágenes de la pierna de palo, del parche en el ojo o del garfio reemplazando a una mano son muy gráficas acerca de lo difícil de la operatoria de esos buques. Todo esto iba acompañado de un elevado el número de pérdidas humanas, sobre todo por pecios y hundimientos. Hubo que esperar a las décadas finales del siglo XIX para que los barcos de cascos metálicos a vapor, generado por calderas de alta presión potenciadas con turbinas y propulsados por medio de una hélice empezaran a desbancar a los veleros.

A pesar de que la propulsión a vapor tiene ejemplos ya en el siglo XVIII, ${ }^{2}$ no fue hasta las décadas centrales del siglo XIX que los barcos de vapor comenzaron a reemplazar a los veleros en la navegación ultramarina. El último cuarto del siglo XVIII, contemporáneamente a la época en que James Watt construyó su primera máquina sofisticada movida a vapor, coexistió con los primeros intentos registrados de mover un barco mediante una máquina de esta naturaleza. Pero fue en los Estados Unidos de América, a principios del siglo XIX, donde Robert Fulton (Hartenberg, 2018), un ingeniero de esa nacionalidad, construyó la primera de las embarcaciones que surcaron los grandes ríos y las costas movidas por las conocidas ruedas impulsadas por la presión del vapor. Sin embargo, la navegación de ultramar a vapor no era posible todavía a principios de ese siglo y los grandes veleros seguían dominando el tráfico.

Para que esta sustitución fuese posible, el barco de vapor tuvo que recibir importantes mejoras como hemos visto: la sustitución de la rueda por la hélice, la incorporación de máquinas y turbinas más eficientes y la construcción de cascos de láminas de hierro unidas por remaches. Con estas mejoras los barcos se hicieron más manejables, no tenían que malgastar su capacidad de carga acumulando enormes cantidades de combustible (o repostar muy a menudo) y se convirtieron en más rápidos y seguros. Uno de los avances tecnológicos producidos a finales del siglo XIX fue el desarrollo de la turbina compuesta de vapor, inventada por el británico Charles Algernon Parsons y adaptada para su uso naval en 1897 (Britannica, 2018).

2 Generalmente se admite que la máquina de vapor aplicada a la navegación tiene su origen en las utilizadas para el achique de las minas atribuyéndose a Jouffroy d'Abbans su primera adaptación a una nave fluvial (el Palmipède, realmente eso parecía, de trece metros de eslora) en 1766 en Francia, desarrollo que fuera interrumpido por la Revolución Francesa (Britannica, 2013). 
Fue en las últimas décadas del siglo XIX que los barcos de vapor se transformaron en piezas insustituibles en fenómenos como el afianzamiento de un mercado mundial o en los intensos procesos migratorios (Cohn, 2005, p. 469) que llevaron a varios millones de europeos a poblar Argentina, Chile, Australia o, sobre todo, los Estados Unidos de América.

Desde que desplazó a la navegación a vela, el buque a vapor alimentado a carbón fue durante unas siete décadas el impulsor de uno de los cambios más trascendentales que ha tenido la navegación y en la transformación de la logística portuaria. En efecto, en los más importantes puertos del mundo fue preciso realizar importantes obras de infraestructura para recibirlos (Konvitz, 1994), entre otras novedades. Como afirma este autor:

"La reducción de las tarifas de flete y la expansión de la capacidad de los barcos y los servicios trajeron considerables beneficios a la economía urbana. Pero el crecimiento del tráfico también fue un factor en las olas de migración, y problemas de salud pública, congestión de embarcaciones, viviendas precarias, huelgas, y el conflicto sobre las estrategias para el desarrollo"(Konvitz, 1994, p. 293).

En su etapa inicial los vapores consumían gran cantidad de carbón, 4 o 5 kg por Hp (Valdaliso, 1992, p. 63) y tenían una maquinaria muy pesada y unas calderas de grandes dimensiones que reducían considerablemente el espacio disponible para la carga. Además, su tripulación requería de un considerable número de "fogoneros", es decir las personas que alimentaban y mantenían el fuego en las calderas de las máquinas de vapor. En islas estratégicas del atlántico, debían generarse y mantenerse enormes depósitos de carbón para completar la carga de combustible en los viajes atlánticos, obligando a los vapores a realizar largas escalas en ellas (se cargaban a mano) antes de la larga singladura hasta América. Dada la limitada autonomía de los vapores, era imprescindible disponer de estas fuentes de combustible convenientemente situadas a lo largo de las rutas para evitar saturar las bodegas de carbón a expensas de la carga. Las islas del Atlántico Ibérico (Madeira, Canarias y Cabo Verde y, en menor medida, las Azores), enclavadas a medio camino del Océano, cumplieron convenientemente esta función de estaciones para repostar aquel combustible, lo que les generó problemas socioeconómicos al dejarse de utilizar este combustible (Suárez Bosa, 1995, p. 139). También lo hicieron las islas de Ascensión, Santa Elena e incluso las Malvinas (Minchinton, 1985, p. 573).

A pesar de los sucesivos perfeccionamientos que fueron mejorando la utilización de la energía del vapor, la sustitución de las embarcaciones de vela por los vapores -al menos en Argentina (Mateo \& Nogueira, 2014)- fue paulatina, con un largo período en que convivieron ambos sistemas incluso de forma combinada a bordo (ver Figura 2). Las flotas de grandes veleros de madera o hierro no desaparecieron en el tráfico de ultramar mundial hasta los años 1925-1930, cincuenta o más años después de la aparición de los barcos a vapor, como afirma el historiador vascongado Jesús Valdalizo: "El cambio de 


\section{J. A. Mateo}

la vela y la madera al vapor y el hierro fue sísmico en su efecto final, pero el proceso fue muy lento, con innumerables superposiciones de tradición e innovación, de viejas y nuevas prácticas" (Valdaliso, 1992, p. 64).

\section{El buque a motor diésel}

En la década de 1890 la industria petrolera buscaba un motor económico para la distribución de combustible alrededor del mundo. La solución fue encontrada por el ingeniero alemán Rudolf Diesel, quién en febrero de 1898 concedió licencias exclusivas para construir sus motores en Suecia y Rusia a Emanuel Nobel. Una planta de motores del grupo económico Nobel en San Petersburgo fue un éxito inmediato; comenzó con un motor diésel para bombas industriales para oleoductos y pronto se proyectó al mercado masivo de motores de molinos de harina (Gardiner \& Greenway, 1994, p. 157).

En 1902 Karl Hagelin, "un veterano del Volga y en algún momento visionario”, según Robert Tolf, (1975, p. 138), sugirió el uso de los motores diésel para propulsar las barcazas de río. Él imaginó el envío directo del petróleo a través de una ruta de 1800 millas desde San Petersburgo a Finlandia por el Volga. Hagelin reclutó al arquitecto naval Johny Johnson de Gotemburgo para diseñar la nave. El casco del buque fue construido en Suecia y su propulsión montada en San Petersburgo. Inició las operaciones comerciales en la primavera de 1903, con el nombre de Vandal. En su viaje inaugural fue accidentalmente dañado, pero una vez reparado sirvió en la ruta del Volga durante diez años. Estas embarcaciones se dedicaban a llevar petróleo desde Bakú, en la costa del Mar Negro, por el Volga a San Petersburgo, una distancia de unos 3.000 kilómetros y una excelente referencia para el nuevo motor (Gardiner \& Greenway, 1994, p. 158).

Para Diésel, dicen Gardiner \& Greenway, (1994, p. 158)' el petrolero de río diseñado por Hagelin y Johnson para Branobel (The Nobel Brothers Petroleum Company), fue el primer navío de este tipo. El Sarmat, más grande, con cuatro motores de $180 \mathrm{hp}$, fue lanzado el verano siguiente. Las nuevas naves atrajeron el interés público y profesional y suscitaron nuevos pedidos. El personal de la planta se expandió a más de mil hombres, pero el crecimiento trajo problemas de gestión. Hagelin no lograba convencer a Emanuel Nobel sobre el futuro de los transportes impulsados por diésel y la conveniencia de convertir a la flota ya existente de vapor a los motores diésel. Su propuesta fue rechazada por el empresario sueco y Hagelin renunció, para aceptar el cargo de cónsul general de Suecia en San Petersburgo.

A pesar de estos traspiés, en 1907 Hagelin y Johnson diseñaron un petrolero de 4.500 toneladas que ofrecieron otra vez a Emanuel Nobel quien volvió a rechazarlo. Los inventores vendieron sus planos a Merkulyev hermanos de Kolomna (Rusia) quienes construyeron el verdadero primer petrolero de navegación marítima impulsado por diésel del mundo, el Mysl, en 1908. Este hecho, por fin, obligó a Emanuel Nobel a concederle Hagelin la necesidad de modernizar la flota de la compañía que alcanzó 315 buques en 1915. 
El barco danés Selandia, que entró en servicio en 1912, también disputa la primacía de primer buque marítimo de motor. Fue construido en Burmeister \& Wain en Copenhague y botado el 04 de noviembre de 1911. Su viaje inaugural fue desde Copenhague a Bangkok en 22 de febrero de 1912. Construido para el transporte de carga y pasajeros, el Selandia tenía "muy amplios y bastante lujosos" camarotes para 20 pasajeros de primera clase, cabinas con literas-single de "tamaño excepcional, con aseo y baño para cada dos camarotes, y una característica adicional: habitaciones de los criados con conexión privada con los camarotes de sus amos (MAN Diesel \& Turbo, 2012).

Después de la Gran Guerra, se efectuaron avances significativos, especialmente en el perfeccionamiento de la propulsión turboeléctrica. Durante la II Guerra Mundial, la soldadura sustituyó a los remaches en la construcción naval. Y pocos años después el vapor fue desapareciendo de los puertos.

\section{La navegación a vapor en Argentina}

En los primeros censos nacionales se puede observar la intensidad con que los vapores se fueron haciendo presentes en los puertos bonaerenses (ver Figura 3). Como puede observarse en la Tabla 1, los vapores componían un insignificante porcentaje del total en 1869 , pero ya superaban el 10\% de las toneladas de registro bruto (TRB) de porte.

En ese momento temprano -y a pesar de que los buques a vapor movidos por ruedas o por hélices ya había sino muy utilizados en la "Guerra Guazú" o "Guerra del Paraguay" o "Guerra de la Triple Alianza" por las armadas en conflicto- ${ }^{3}$ podemos ver que si bien su porte significaba un avance monumental en la arquitectura naval el paisaje portuario todavía era dominado por las velas. En el puerto de Buenos Aires, de lejos el más importante del país, se encontraban sólo doce de ellas, con una media de porte de 357 TRB de promedio y

Tabla 1. Cantidad y TRB de buque a vela y a vapor en los puertos bonaerenses el d\{ia del censo de 1869 .

\begin{tabular}{|l|c|c|c|c|}
\hline \multicolumn{1}{|c|}{ Puerto } & Cantidad Vapor & TRB Vapor & Cantidad Vela & TRB Vela \\
\hline Buenos Aires & 12 & 4294 & 232 & 77282 \\
\hline Tigre & 21 & 3895 & 77 & 3067 \\
\hline San Nicolás & 2 & 1800 & 47 & 2525 \\
\hline Zárate & 5 & 1748 & 34 & 5541 \\
\hline Riachuelo & 4 & 65 & 795 & 16059 \\
\hline Ajó & & & 4 & 117 \\
\hline San Pedro & & & 15 & 377 \\
\hline Total general & 44 & 11802 & 1204 & 104968 \\
\hline
\end{tabular}

Fuente: Primer Censo Nacional de la República Argentina.

3 Del Paraguay, Argentina, Brasil y Uruguay. 
21, con la mitad de ese tamaño, en el puerto de Tigre -un puerto muy menor, seguramente para el traslado fluvial de frutos del Delta del Paraná hacia los mercados de Buenos Aires. Curiosamente en San Nicolás, aunque se encontraban solamente 2 de éstas, sumaban en conjunto, 1800 TRB, con una media casi tres veces superior a las presentes en Buenos Aires. En consecuencia, no podemos afirmar una presencia importante de este tipo de buques en este período, pero sí una al menos relativa.

A partir de 1877 fue incorporándose en el Río de la Plata la innovación franco-uruguaya del frigorífico aplicado a la embarcación. El viaje del buque Le Frigorifique a través del Atlántico, puede considerarse un hito que marca el inicio de una verdadera revolución a nivel industrial. El inventor del sistema de refrigeración mecánica y armador del buque, el ingeniero francés Charles Tellier, fue acompañado por dos uruguayos que colaboraron en este proyecto: Francisco Lecocq y Federico Nin Reyes. Como dice Manuel Zamora Carranza: "Era la primera vez en la historia que una carga de productos perecederos cruzaba el Océano Atlántico de norte a sur atravesando el Ecuador sin problemas" (Zamora Carranza, 2004, p. 284). ${ }^{4}$

El viaje de retorno no fue tan auspicioso. Cuenta Horacio Giberti que la Sociedad Rural hizo una colecta que unida a una donación del gobierno bonaerense permitió comprar un lote de novillos y cederlos a la empresa para su viaje de retorno. No pensaban los estancieros en el ovino, aunque sí lo hizo la empresa. Con los fondos provenientes de los cueros y sebo del lote de bovinos obsequiado adquirió 200 capones. Tras azarosa travesía e inconvenientes con las máquinas, el cargamento llegó en malas condiciones (Giberti, 1985, p. 159), sin embargo la experiencia no se detuvo y a los pocos años el envío de carne ovina congelada a Europa fue una realidad que movilizó fuertemente la industria frigorífica de Buenos Aires, ciudad y provincia.

En 1895 (Tabla 2) ya había en Buenos Aires 194 vapores con una media de 545 TRB y mientras que los 26 de La Plata (donde estaban instalados varios frigoríficos de capitales británicos) doblaban esa media. Este momento de auge del puerto construido a la vera de la recientemente fundada capital de la provincia de Buenos Aires fue dado por la alternativa a las dificultades conocidas de la utilización del coqueto Puerto Madero de Buenos Aires, que quedó obsoleto desde su inauguración ya que no contemplaba el crecimiento de los vapores, además de no tener todos sus diques y canales habilitados a esa fecha.

Ante las sensibles transformaciones en la navegación y en la arquitectura naval de finales del siglo XIX, en 1899, el gobierno argentino, concibió un extenso proyecto de mejoramiento fluvial y portuario y solicitó al gobierno de los Estados Unidos que recomendara a un ingeniero que vendría a la Argentina para asistirlo con su consejo en la formulación y ejecución de los planes. El elegido fue el ingeniero civil Elmer Lawrence Corthell, quien realizó un extenso estudio en el que comparó a ambos países, asimilando el potencial productivo de la Argentina a la de su país y a la cuenca del Plata con la del río Mississippi y resaltaba por tanto las posibilidades de navegabilidad de los ríos sudamericanos (Corthell, 1903, p. 439). Corthell aconsejó extender el Puerto Madero hacia el este, adosándole una serie de dársenas

4 Precisamente, en el Uruguay se celebra los días 29 de mayo el “Día Nacional de la Carne” por el arribo a Montevideo del vapor de marras el 29 de mayo de 1877 . 
en peine, lo que entrañaba reconciliar el diseño del comerciante Eduardo Madero con el de su mayor crítico, el ingeniero Luis Augusto Huergo, (Silvestri, 2003, p. 96).

El "Puerto Nuevo" de Buenos Aires comenzaría a desarrollarse desde entonces, junto a muchas mejoras en otros puertos existentes como los del complejo portuario de Bahía Blanca $^{5}$ y con la construcción desde cero de los importantes puertos de Mar del Plata y de Quequén, estos tres sobre el Océano Atlántico de la provincia de Buenos Aires. En Bahía Blanca aparecieron por primera vez en los puertos atlánticos los vapores ultramarinos con un porte importante (una media de 849 TRB). El puerto de San Nicolás (dicho sea de paso, uno de los más estimulados por la recientemente provincializada Buenos Aires junto al de La Plata y el de Bahía Blanca), ${ }^{6}$ volvió a destacarse por el porte de sus dos únicas embarcaciones que sumaban en este caso 2465 TRB. En el mismo sentido, la embarcación única presente

Tabla 2. Cantidad y TRB de buque a vela y a vapor en los puertos bonaerenses el día del censo de 1895.

\begin{tabular}{|c|c|c|c|c|}
\hline Puerto & Cantidad vapor & TRB Vapor & Cantidad Vela & TRB Vela \\
\hline Buenos Aires & 194 & 105820 & 814 & 67683 \\
\hline La Plata & 26 & 27818 & 80 & 17545 \\
\hline Bahía Blanca & 9 & 7641 & 11 & 2996 \\
\hline San Nicolás & 2 & 2645 & 35 & 2358 \\
\hline Campana & 4 & 1664 & 22 & 1935 \\
\hline Zárate & 1 & 1606 & 19 & 4203 \\
\hline Tigre & 11 & 1214 & 16 & 143 \\
\hline San Fernando & 9 & 935 & 135 & 1629 \\
\hline Ajó & & & 20 & 972 \\
\hline Atalaya & & & 25 & 671 \\
\hline Baradero & & & 28 & 661 \\
\hline Mar del Plata & & & 10 & 46 \\
\hline Quequén & & & 7 & 140 \\
\hline Ramallo & & & 3 & 527 \\
\hline San Pedro & & & 19 & 787 \\
\hline Total general & 256 & 149350 & 1244 & 102296 \\
\hline
\end{tabular}

Fuente: Segundo Censo Nacional de la República Argentina.

5 Los puertos de Ingeniero White, Nacional, Puerto Galván, Puerto Cuatreros, Arroyo Pareja o Puerto Rosales y la imponente Base Naval de Puerto Belgrano.

6 "Tres órdenes de hechos, puede decirse, favorecen en primer término el desarrollo de un lugar: primero, la situación geográfica, tomada en absoluto; segundo, sus condiciones típicas, físicamente consideradas; y tercero, la facilidad de relaciones, o sea la fuerza de atracción que pueda ejercitar sobre comarcas circunvecina, más o menos vastas. Estas ventajas naturales pueden ser ayudadas luego artificialmente con la acción administrativa, ó por la reconcentración de capitales. En tales circunstancias, se encuentran para la provincia los puertos de San Nicolás en el Paraná, Bahía Blanca en el Atlántico, y la Ensenada en el Plata” (De la Fuente, 1883, p.14). 
en Zárate, con 1664 TRB impresiona por su volumen además de por el puerto en el cual fue censado, seguramente vinculado al frigorífico Anglo instalado allí desde años antes. Esta misma industria explica la presencia de vapores en San Nicolás y Campana.

Hacia 1914 (Tabla 3) y con 610 embarcaciones -con un promedio de 740 TRB- Buenos Aires se destacaba y sobresalía largamente con la presencia de vapores. De similar porte medio eran los 89 que amarraban en el puerto de La Plata. El complejo portuario de Bahía Blanca acumulaba vapores en 4 de sus puertos, 11 en el Muelle Nacional, 8 en Puerto Galván, 23 en Ingeniero White y 9 en Arroyo Pareja (hoy Puerto Rosales) que promediaban 570 TRB en conjunto. Los 11 vapores de Bahía Blanca alcanzaban las 1224 TRB de promedio y las 8 de Galván la friolera de 1624 TRB. Con 51 vapores el complejo portuario atlántico se había convertido en el tercer puerto de la región bonaerense, aunque todavía estaban lejos tanto en cantidad como en registro bruto del de La Plata. Los veleros se habían reducido en cuanto a su registro bruto a un 20\% del total (cuando en 1895 había rondado el 50\%), si bien en número su presencia seguía siendo significativa.

El censo de 1914 nos permite también una mirada diacrónica de este proceso, si bien no podemos desagregar por puertos, entre 1880 a 1914. Si tomamos como variable la cantidad de buques (Gráfico 1) vemos que el cruce de tijeras entre una y otra propulsión se dio en el cambio de siglo. Mientras el número de vapores seguía una tendencia creciente el de veleros parece haberse estabilizado bastante, aunque sin extinguirse. ${ }^{7}$

Sin embargo, si nos remitimos a la capacidad de esas naves (Gráfico 2) el estancamiento de los veleros es más pronunciado entre 1880 y 1914 y en los vapores tuvo un crecimiento sostenido desde un punto de casi contacto en 1880 con una leve caída en 1911 retomada con potencia al año siguiente.

En síntesis, podemos decir que el paso del vapor a la vela fue cierto después de 1880, pero quizás su difusión fue bastante más lenta -como suele serlo con toda incorporación

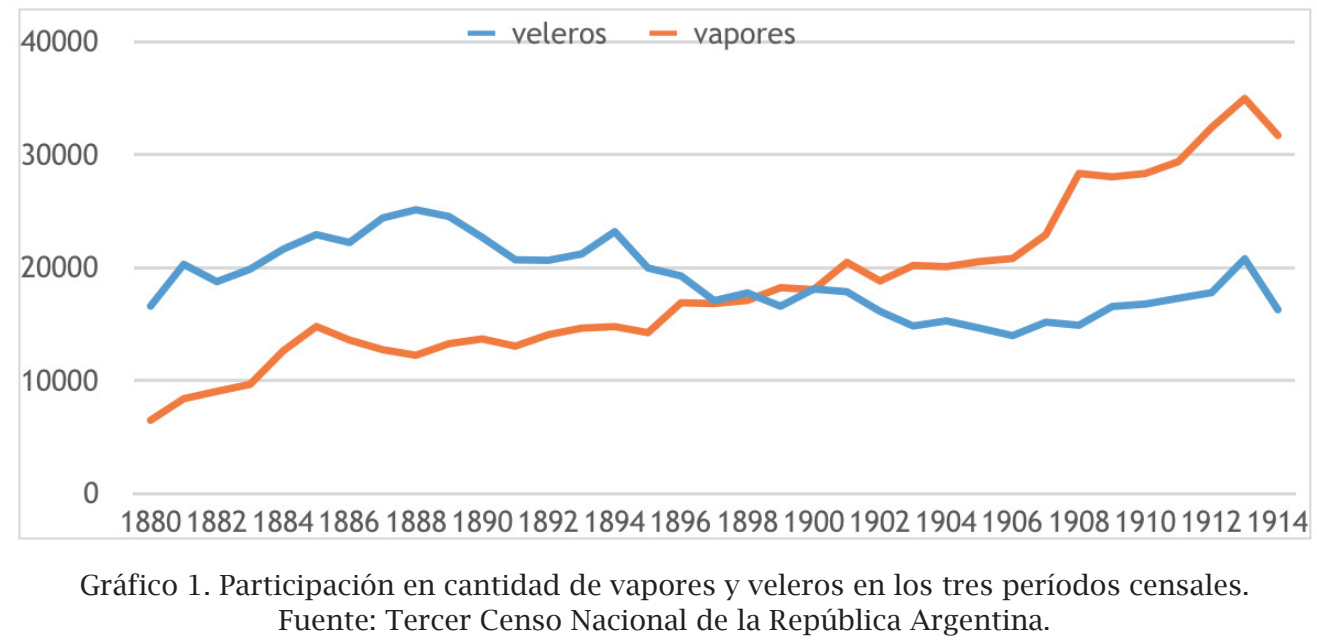

La caída en ambos en 1914 puede deberse tanto a la Gran Guerra como a que no se registró el año completo. 
DE LA VELA AL VAPOR, DEL VAPOR AL MOTOR

Tabla 3. Cantidad y TRB de buque a vela y a vapor en los puertos bonaerenses el día del censo de 1914.

\begin{tabular}{|c|c|c|c|c|}
\hline Puerto & Cantidad vapor & TRB vapor & Cantidad vela & TRB vela \\
\hline Buenos Aires & 610 & 450707 & 1188 & 135827 \\
\hline La Plata & 89 & 65647 & 212 & 3458 \\
\hline Bahía Blanca & 11 & 13466 & 21 & 5800 \\
\hline Galván & 8 & 12993 & 8 & 1149 \\
\hline Zárate & 29 & 12957 & & \\
\hline San Nicolás & 28 & 11681 & & \\
\hline Vuelta de San Antonio & 3 & 3702 & & \\
\hline Campana & 40 & 3003 & 159 & 2708 \\
\hline Mar del Plata & 12 & 2598 & 82 & 391 \\
\hline Ingeniero White & 23 & 1601 & 21 & 72 \\
\hline San Fernando & 232 & 1500 & & \\
\hline Arroyo Pareja & 9 & 1067 & 2 & 441 \\
\hline Tigre & 512 & 1010 & & \\
\hline Sarandi & 14 & 402 & & \\
\hline San Pedro & 9 & 225 & & \\
\hline Baradero & 3 & 126 & 18 & 1450 \\
\hline Bahía San Blas & 6 & 76 & 3 & 774 \\
\hline Patagones & 21 & 72 & 60 & 132 \\
\hline Quequén & 3 & 15 & 11 & 5 \\
\hline Ajó & & & 1 & 25 \\
\hline Atalaya & & & 5 & 1503 \\
\hline Miramar & & & 2 & 3 \\
\hline Quilmes & & & 3 & 1 \\
\hline Ramallo & & & 17 & 36 \\
\hline Romero Chico & & & 1 & 136 \\
\hline Total general & 1662 & 582848 & 1816 & 153912 \\
\hline
\end{tabular}

Fuente: Tercer Censo Nacional de la República Argentina.

tecnológica- que la que se le suele adjudicar normalmente y no significó la atenuación de la cantidad de veleros (bergantines, goletas, pailebotes, queches, lugres, cuters, balleneros, balandras, etc.) ni mucho menos su desaparición. La iconografía portuaria del siglo XX nos ha dejado suficientes testimonios de la convivencia de ambos tipos de embarcaciones en los diferentes puertos.

El motor a explosión en los puertos argentinos

El censo de 1914 no registra embarcaciones a motor, sin embargo, ya existían. A 


\section{J. A. Mateo}

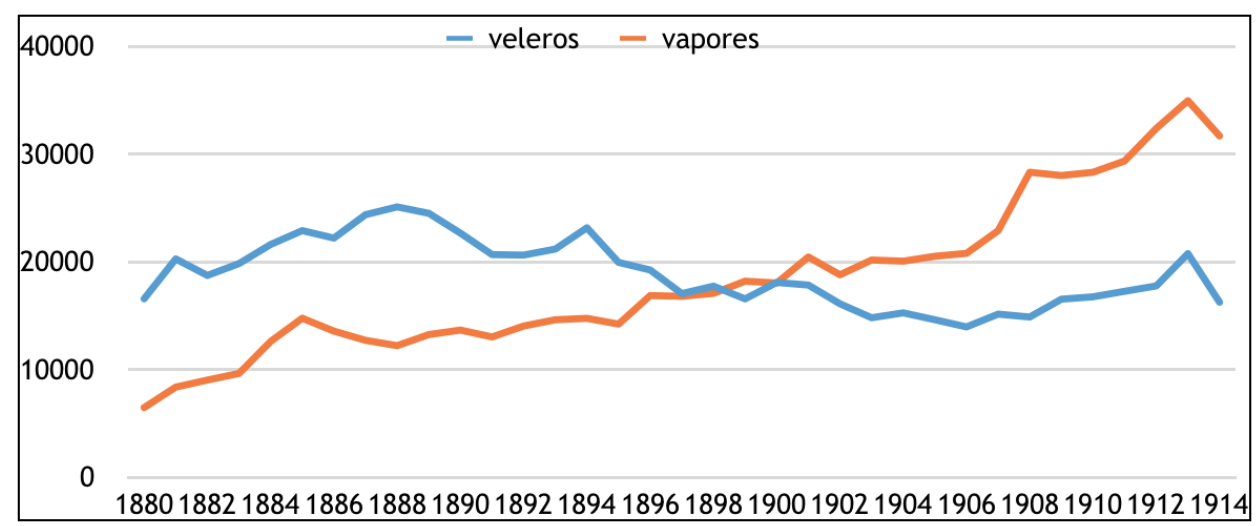

Gráfico 2. Participación en TRB de vapores y veleros en los tres períodos censales. Fuente: Tercer Censo Nacional de la República Argentina.

principios del siglo XX la armada argentina tenía una nutrida flota de este tipo. Mientras tanto la flota mercante, junto al ferrocarril y a las usinas eran los principales consumidores de carbón, que se importaba desde Inglaterra. El tráfico naviero de ese comercio triangular tan conocido por la historiografía (Fodor \& O’Connell, 1973) permitía a los buques británicos que llegaban cargados de carbón tener disposición de bodega de retorno para actuar como transportes de granos hacia otra nación cobrando flete (Mateo, 2014b).

Al hallarse petróleo en la zona patagónica de Comodoro Rivadavia en la provincia de Chubut, a miles de kilómetros de Buenos Aires, las autoridades navales hicieron modificar las máquinas de los buques para utilizar petróleo en vez de carbón y dejar de depender de las importaciones del carbón de Gales. Entre 1914 y 1922 la armada ingresó los cinco primeros buques petroleros para trasladar el oro negro desde allí (Mateo, 2015c) hasta Bahía Blanca o la cercanía de Buenos Aires. Cuatro de ellos pasaron a depender de YPF, la primera empresa petrolera estatal del mundo creada en 1922.

La tendencia mundial ya iba en ese sentido. Muchas compañías de carga rápidamente operaron con flotas equipadas enteramente con motores diésel, pero hubo algunas que resistieron fuertemente la tendencia. Probablemente el Reino Unido mantuvo altos porcentajes de esta flota para asociar a su industria naval con su liderazgo mundial en producción de carbón de Escocia, Inglaterra y Gales que mantuvo hasta bien avanzado el siglo XX. El vapor fue también la regla en la flota mercante de los Estados Unidos de América, posiblemente debido a la menos que satisfactoria experiencia con motores así equipados del US Shipping Board's Conversion Programme de después de la Primera Guerra Mundial; pero también por la posición defendida por los grandes intereses de la ingeniería eléctrica estadounidenses que proporcionaba paquetes de propulsión a vapor como una actividad secundaria a la producción de las centrales eléctricas de servicios públicos.

Así se llegó a la mitad de siglo y a la segunda posguerra con una flota mixta al igual que había ocurrido con el velero y el vapor. Pero a partir de entonces el motor comenzó su supremacía. A finales de los años 1950, se construyeron ya varios motores capaces de aplicar 
20.000bhp a una sola hélice y con diámetros de cilindro de 900 mm (35.5’), para la instalación en buques cisternas grandes y rápidos. Ya en los años 60, el comercio entre Europa y el Lejano Oriente estaba exigiendo barcos de carga con velocidades de 20 nudos, y la industria recibió el llamado y muchas de estas impresionantes máquinas fueron construidas para este cometido.

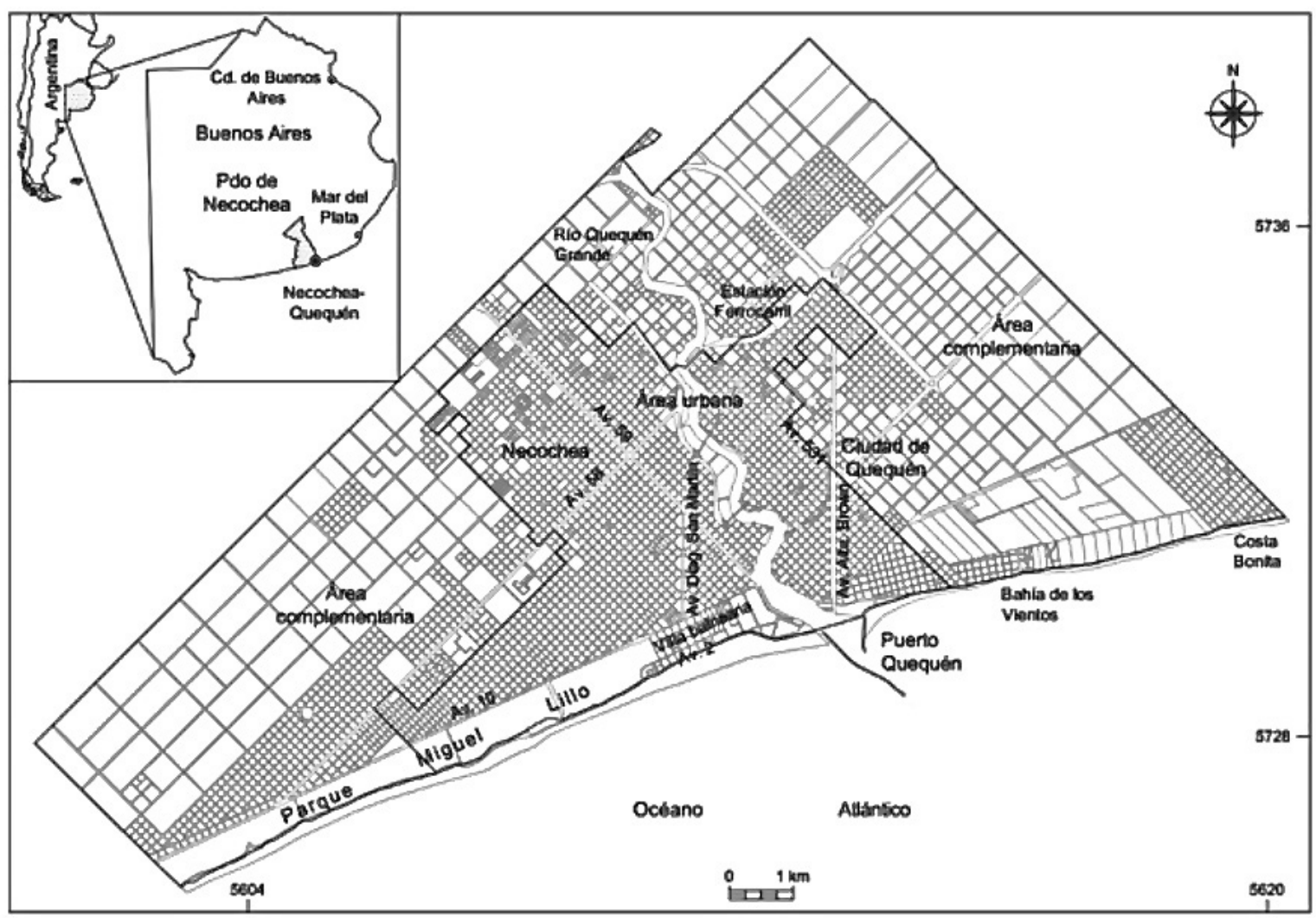

Figura 1. Ubicación y detalle de Puerto Quequén Fuente: Elaboración propia.

\section{La transición del vapor al motor diésel en puerto Quequén}

Como adelantábamos en la introducción, para medir y evaluar la transición entre un sistema de propulsión a otro requerimos de series completas las cuales o no existen o son difíciles de construir. Afortunadamente tanto la aduana como la policía portuaria de Puerto Quequén conservan buena parte de los registros de entrada y salida de buques y hemos podido construir una serie completa desde la inauguración de ese puerto en 1921.

¿Por qué es importante este puerto si bien apenas pertenece al top ten de los puertos exportadores de Argentina? La respuesta es sencilla y a su vez, creemos, de sumo interés hasta el presente en un país agroexportador. Si bien los puertos más importantes de Argentina se encuentran en la denominada "zona núcleo" de la producción agraria que se encuentra en 
el litoral fluvial que se extiende entre los puertos de Santa Fe al Norte y La Plata en el sur, mientras los puertos atlánticos (Mar del Plata, Quequén y Bahía Blanca) son progresivamente axiales a esta zona, la sucesiva necesidad de calado (con un francobordo menor en aguas cálidas y dulces de los ríos) por parte de la arquitectura naval permite una carga más limitada en los puertos fluviales que en los marítimos. En efecto, mientras el calado fluvial alcanza en las mejores circunstancias los 35', Quequén y Bahía Blanca pueden ofrecer hasta más de 40'. Ante esta situación -dejando de lado al puerto de Mar del Plata cuyo destino ha sido básicamente la exportación extractiva pesquera (Mateo, 2015a)- las embarcaciones han debido históricamente realizar una carga importante en los puertos fluviales pero también a completar la carga (topping off) tanto en Quequén como en Bahía Blanca. Esto incrementa la representatividad de este puerto mucho más allá de los producido en su hinterland, que a su vez integra la nada despreciable superficie de cuatro millones de hectáreas (Mateo, 2014a).

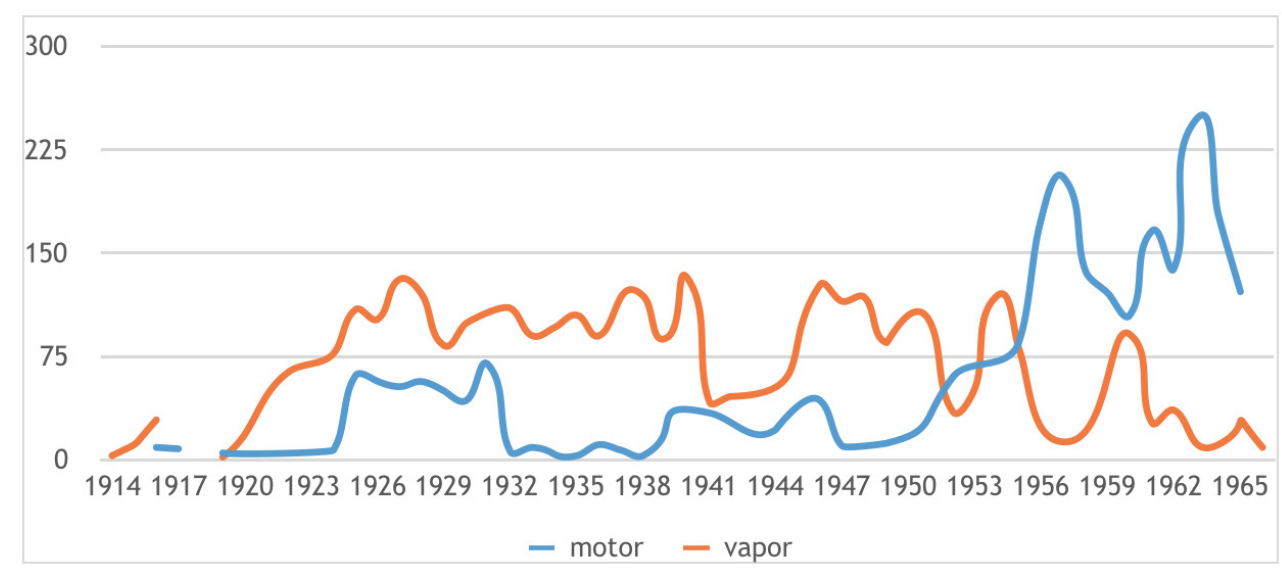

Gráfico 3. Cantidad de embarcaciones y modo de propulsión en Puerto Quequén (1921-1966). Fuente: Libros de entrada y salida de buques de la Prefectura Nacional en Puerto Quequén.

En el Gráfico 3 podemos ver varias cosas. En principio la presencia tanto de vapores como de embarcaciones propulsadas a motor durante la construcción del puerto. Las primeras eran naves de las empresas que realizaban el transporte de mercancías y personas en el cabotaje interior previo al inicio de las obras portuarias y del desarrollo vial ocurrido a partir de 1930. En segundo lugar, vemos una convivencia entre ambos modos de propulsión que, en número de embarcaciones, aunque con una subordinación evidente del motor al vapor hasta el año 1951 en que se produjo un primer cruce de tijeras entre ambos modos. Sin embargo, podemos ver que esa transición se hizo efectiva entre ese año y 1955, cuando se inició otro período de convivencia, pero ahora subordinando al vapor hasta 1966 en que evidentemente los armadores dejaron de operar con este tipo de propulsión.

Vemos tanto en el Gráfico 3 como en el siguiente un crecimiento de la presencia de vapores que podemos asignar a la creación de la OPEP 1960, con un considerable incremento en los valores del crudo, lo que puede explicar el reflujo de esos años en la navegación a motor. 


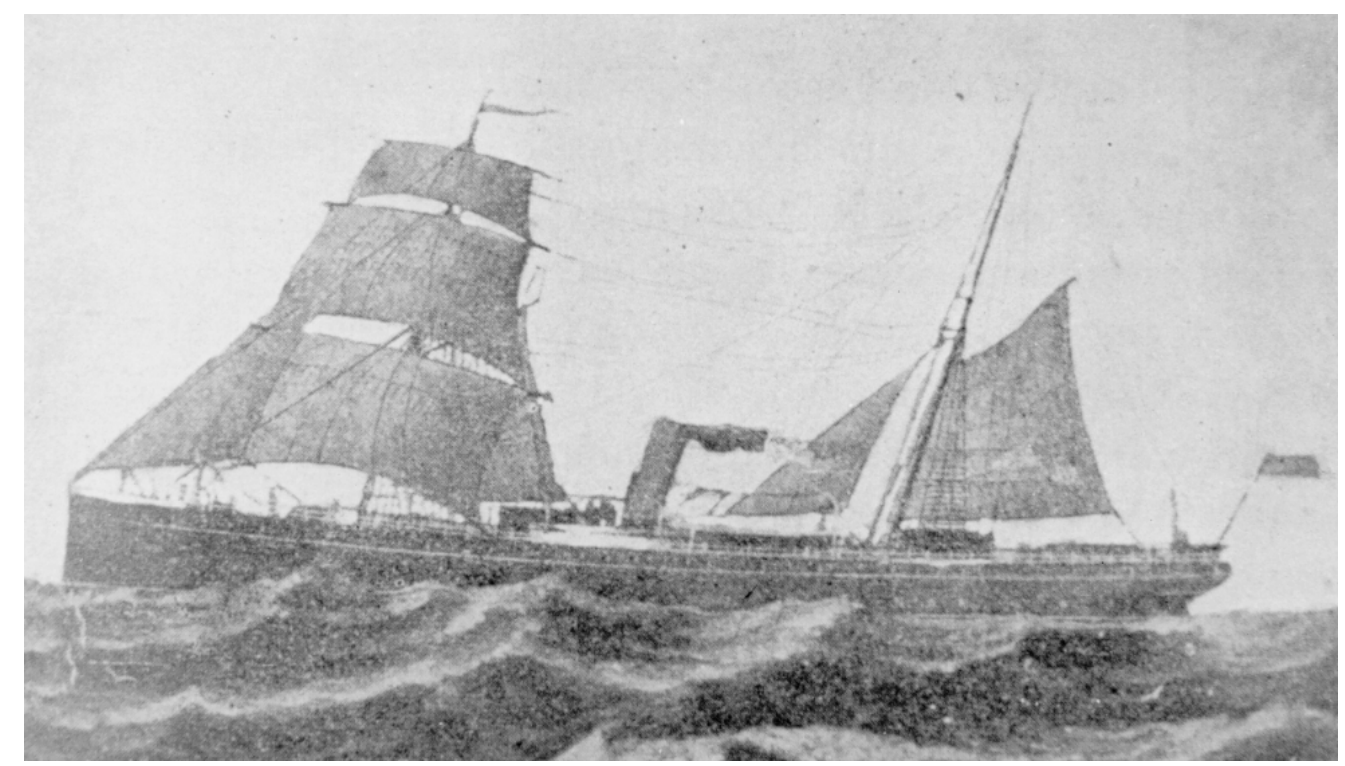

Figura 2. Transporte mixto (vela-vapor) Villarino, Puerto Quequén, 1923. Fuente: Fundación Histarmar (http://www.histarmar.com.ar/).

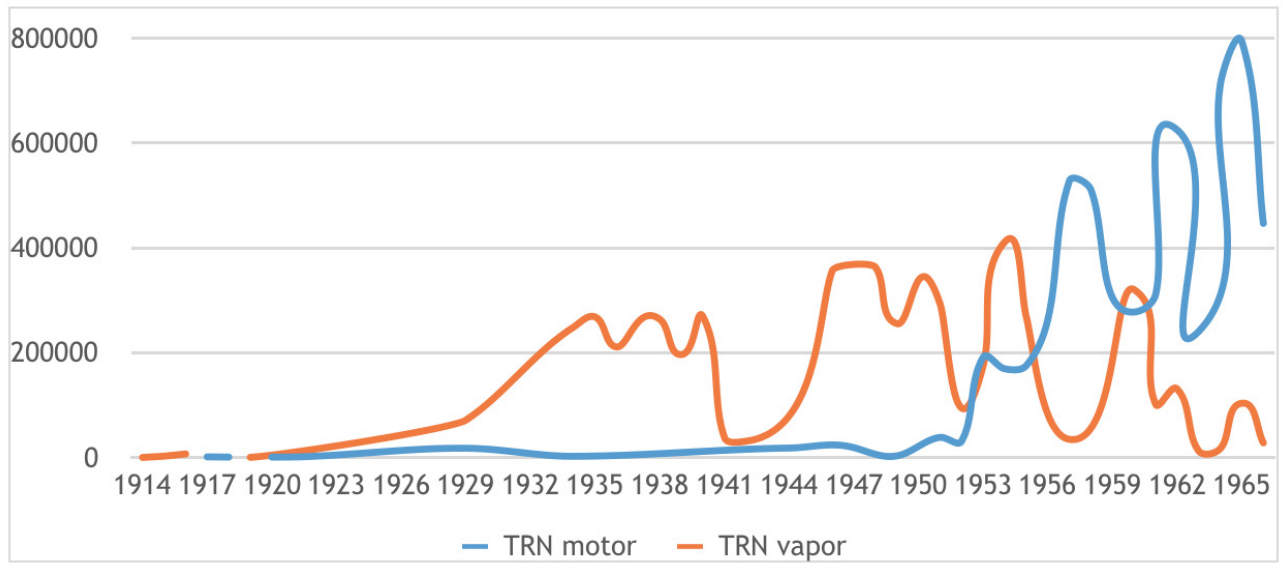

Gráfico 4. TRB de las embarcaciones y modo de propulsión en Puerto Quequén (1921-1966).

Fuente: Libros de entrada y salida de buques de la Prefectura Nacional en Puerto Quequén.

El Gráfico 4 mide este proceso mediante el porte de las naves. El resultado es muy parecido, lo cual destaca el factor concreto de la propulsión en los costos operativos más allá del tamaño de las naves.

La inmensa mayoría de los buques que han pasado por Puerto Quequén son graneleros (bulk carriers), es decir, buques diseñados para transportar cargas secas a granel, tales como minerales o cereales. Tienen una sola cubierta, bodegas sin entrepuentes y grandes escotillas. Actualmente los hay desde 5.000 hasta 200.000 toneladas de carga y los más usados por su rentabilidad son los conocidos como tipo panamax, que oscilan entre 60.000 y 70.000 toneladas. Por lo general no tienen grúas, porque su carga se embarca y 
desembarca en terminales portuarias especiales con sistemas de elevadores que permiten operar con gran rapidez y practicidad, reduciendo así tiempos (de días a horas) y, por ende, costos. Progresivamente se han ido sumando buques cisterna apropiados para el transporte de aceites vegetales.

Todo trabajo historiográfico debería comenzar por una periodización de los fenómenos que se intenta comprender, y el estudio de caso permite aportar a ello. Una periodización es una hipótesis de trabajo basada en una información de sondeo. Para este caso, fundado en saltos cuantitativos importantes, ponemos su inicio en el año 1952 y dado que desaparecieron para siempre luego-, 1966 fue el año en que la transición fue terminada. Podemos ver también en el Gráfico 4 un aumento de los vapores entre 1924 y 1932, una caída durante la II Guerra Mundial y una recuperación luego de ella para volver a caer en la inmediata posguerra hasta tiempos del segundo plan quinquenal del gobierno peronista durante el cual se da la transición. En efecto, las motonaves comenzaron a crecer en importancia hacia 1952 para no detener su incremento.

Medidos en porte de las embarcaciones el salto es mucho más claro y se lleva a cabo entre 1951 (15,4\% de buques a motor) y 1952 (41,7\% de motonaves). La Tabla 4 resume estos momentos durante seis períodos seleccionados (ver Figura 4).

La última embarcación a vapor partió de Puerto Quequén, el "Campero" de bandera argentina, lo hizo rumbo a El Callao (Perú) el 8 de septiembre de 1966. En 1967 podemos anunciar que la navegación a vapor es ya sólo un recuerdo para Puerto Quequén en la primavera de 1966 y probablemente en muchos otros puertos. La Tabla 5 señala la fecha, nombre, bandera, porte y destino de los últimos vapores salidos de Puerto Quequén.

Como puede observarse eran mayormente de bandera argentina, en un caso de bandera de conveniencia panameña y en otra de Grecia, uno de los mayores armadores del mundo en esos años. Esto nos remite al análisis de las banderas en la transición que haremos en el punto siguiente.

Tabla 4. Presencia porcentual de embarcaciones y modo de propulsión en Puerto Quequén (1921-1966) en períodos seleccionados.

\begin{tabular}{|c|c|c|c|c|}
\hline \multirow{2}{*}{ Período } & \multicolumn{2}{|c|}{ Cantidad } & \multicolumn{2}{c|}{ TRN } \\
\cline { 2 - 5 } & Motor \% & Vapor \% & Motor \% & Vapor \% \\
\hline $1915-1925$ & 23,2 & 76,8 & 21.4 & 78,6 \\
\hline $1926-1932$ & 34,3 & 65,7 & 17,3 & 82,7 \\
\hline $1933-1939$ & 5,6 & 94,4 & 1,7 & 98,3 \\
\hline $1940-1947$ & 33,5 & 66,5 & 14,9 & 85,1 \\
\hline $1948-1951$ & 11,0 & 89,0 & 5,0 & 95,0 \\
\hline $1952-1966$ & 71,3 & 28,7 & 68,5 & 31,5 \\
\hline
\end{tabular}

Fuente: Libros de entrada y salida de buques de la Prefectura Nacional en Puerto Quequén. 
Tabla 5. Últimos buques a vapor salidos de Puerto Quequén.

\begin{tabular}{|l|c|c|c|c|}
\hline \multicolumn{1}{|c|}{ Fecha } & Buque & Bandera & TRN & Destino \\
\hline $18 / 05 / 1966$ & Sao Paulo & panameña & 4492 & Montevideo \\
\hline $15 / 06 / 1966$ & Khios Star & griega & 6449 & Bahía Blanca \\
\hline $27 / 06 / 1966$ & Córdoba & argentina & 4549 & El Callao \\
\hline $12 / 07 / 1966$ & Navemar & argentina & 1135 & Río de Janeiro \\
\hline $30 / 07 / 1966$ & Mar del Norte & argentina & 2335 & Santos \\
\hline $03 / 09 / 1966$ & Navemar & argentina & 1135 & São Francisco do Sul \\
\hline $07 / 09 / 1966$ & Mar del Norte & argentina & 2335 & Río de Janeiro \\
\hline $08 / 09 / 1966$ & Campero & argentina & 4564 & El Callao \\
\hline
\end{tabular}

Fuente: Libros de entrada y salida de buques de la Prefectura Nacional en Puerto Quequén.

\section{Las banderas de las motonaves pioneras en Puerto Quequén}

En los años de la transición del vapor al motor, concurrieron a Puerto Quequén 2391 buques de carga (no consideramos buques de guerra, pesqueros, frigoríficos, tanques, dragas y otras embarcaciones menores). De ellos, 1755 (73\%) iban impulsados a motor y el resto (636, el 27\%) todavía funcionaban a vapor. Medido en porte de embarcaciones el porcentaje de las motonaves era el mismo. De las 7.820.029 TRN acumuladas en esos años el 73\% fue de buques a motor (5.681.334 TRN) y el 27\% restante (2.138.695 TRN) a vapor.

Una veintena de banderas además de la argentina tuvieron presencia con motonaves en Puerto Quequén durante el período de la transición. Son las banderas nacionales mayoritarias (1410, el 82\%) con sólo un 18\% (310 buques) del "PanLibHonCo" (Pa.nama - Liberia - Honduras

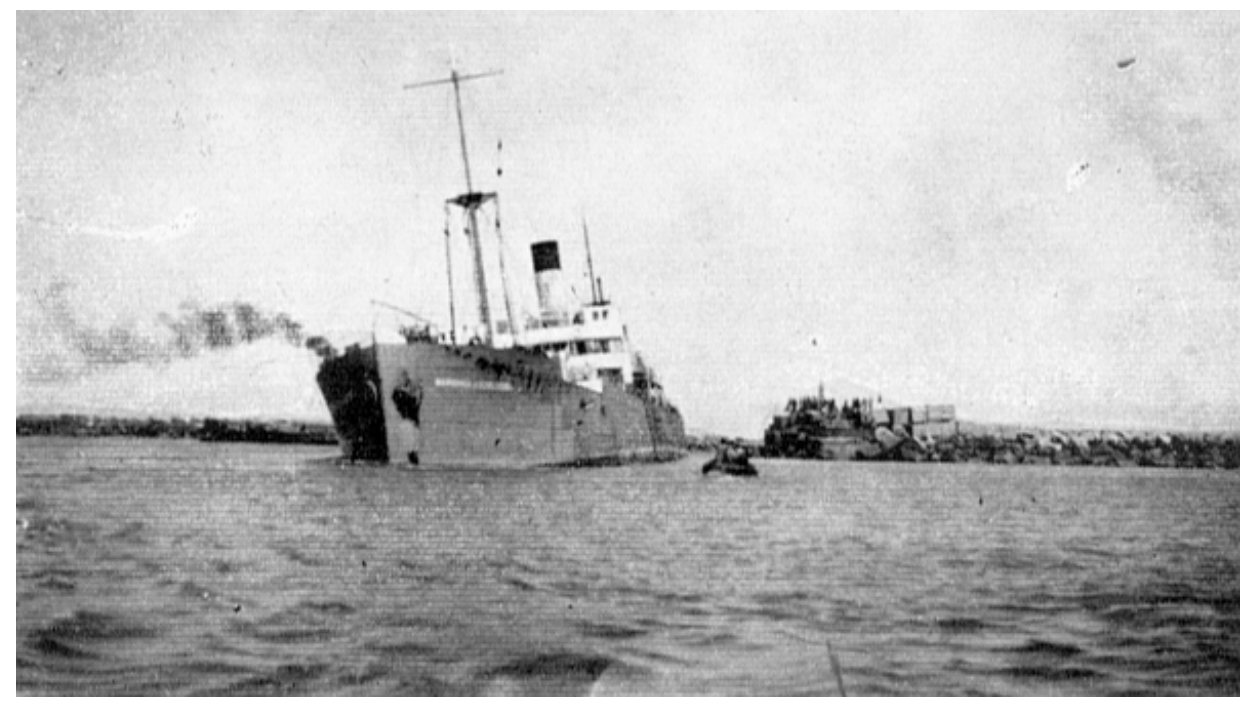

Figura 3. Vapor griego Mariona Goulandris, Puerto Quequén 1923. Fuente: Fundación Histarmar (http://www.histarmar.com.ar/). 


\section{J. A. MAteo}

Tabla 6. Banderas de los buques a motor registrados en Puerto Quequén (1951-1966).

\begin{tabular}{|c|c|c|c|c|c|}
\hline Bandera & Cantidad & Media anual & Bandera & $\Sigma$ TRN & Media anual \\
\hline brasilera & 299 & 21,4 & griega & 958999,7 & 68500,0 \\
\hline griega & 197 & 14,1 & liberiana & 889270,5 & 63519,3 \\
\hline liberiana & 191 & 13,6 & italiana & 847978,0 & 60569,9 \\
\hline italiana & 184 & 13,1 & brasilera & 634986,2 & 45356,2 \\
\hline británica & 143 & 10,2 & británica & 592930,1 & 42352,2 \\
\hline danesa & 120 & 8,6 & panameña & 441752,6 & 31553,8 \\
\hline panameña & 102 & 7,3 & danesa & 382983,1 & 27355,9 \\
\hline noruega & 89 & 6,4 & noruega & 333152,1 & 23796,6 \\
\hline alemana & 83 & 5,9 & alemana & 288863,9 & 20633,1 \\
\hline finlandesa & 72 & 5,1 & holandesa & 199514,8 & 14251,1 \\
\hline holandesa & 55 & 3,9 & finlandesa & 198361,5 & 14168,7 \\
\hline francesa & 51 & 3,6 & francesa & 138373,8 & 9883,8 \\
\hline chilena & 27 & 1,9 & belga & 85910,3 & 6136,5 \\
\hline uruguaya & 24 & 1,7 & española & 74928,4 & 5352,0 \\
\hline belga & 20 & 1,4 & chilena & 68565,3 & 4897,5 \\
\hline sueca & 19 & 1,4 & libanesa & 68374,3 & 4883,9 \\
\hline costarricense & 17 & 1,2 & estadounidense & 66202,7 & 4728,8 \\
\hline libanesa & 16 & 1,1 & costarricense & 58295,5 & 4164,0 \\
\hline española & 14 & 1,0 & sueca & 53752,8 & 3839,5 \\
\hline \multirow[t]{2}{*}{ estadounidense } & 14 & 1,0 & suiza & 49267,0 & 3519,1 \\
\hline & 1737 & 123,9 & & 6432462,6 & 459461,9 \\
\hline
\end{tabular}

Fuente: Libros de entrada y salida de buques de la Prefectura Nacional en Puerto Quequén.

- Costa Rica) las primeras banderas de conveniencia (Mateo, 2015b), que hemos resaltado en la Tabla 6.

La bandera con mayor número de buques a motor fue la de Brasil, socio comercial de Argentina que incrementó el despacho de navíos con trigo desde los puertos cerealeros desde la Segunda Guerra Mundial.

También podemos observar que las embarcaciones de mayor porte llevaban el estandarte griego, aunque las banderas de conveniencia ya comenzaban a dominar el registro de buque y que Liberia, el segundo registro para estas operaciones ya había superado a Panamá, país en el cual nació este artilugio para evadir controles fiscales, sanitarios y evitar la acción de los poderosos sindicatos navieros. Como es bien sabido, las banderas de las navieras poco tienen que ver con las rutas que sus embarcaciones recorren, pasaremos ahora a analizar los destinos de las embarcaciones a motor que partieron de Puerto Quequén durante la transición. 
Los destinos de los buques a motor que zarparon de Puerto Quequén durante la transición

La Tabla 7 resume los destinos de 1055 buques que partieron hacia el exterior entre 1951 y 1966. En primer lugar, destacan los buques despachados hacia el Brasil, casi la mitad de ellas, por los motivos que hemos expuesto, muchos de ellos pertenecientes

Tabla 7. Destinos de los buques a motor registrados en Puerto Quequén (1951-1966).

\begin{tabular}{|c|c|c|c|c|c|}
\hline País de destino & $\mathbf{\Sigma}$ buques & Media anual & País de destino & I TRN & Media anual \\
\hline Brasil & 685 & 48,9 & Brasil & 1134624,09 & 81044,6 \\
\hline Italia & 71 & 5,1 & Italia & 275633,66 & 19688,1 \\
\hline Uruguay & 60 & 4,3 & Uruguay & 200750,25 & 14339,3 \\
\hline Paises Bajos & 48 & 3,4 & Países Bajos & 145944,80 & 10424,6 \\
\hline Alemania & 40 & 2,9 & Alemania & 130113,86 & 9293,8 \\
\hline Perú & 32 & 2,3 & Perú & 121563,53 & 8683,1 \\
\hline Chile & 26 & 1,9 & Chile & 65560,41 & 4682,9 \\
\hline Dinamarca & 18 & 1,3 & Dinamarca & 53450,73 & 3817,9 \\
\hline Francia & 15 & 1,1 & Francia & 44858,67 & 3204,2 \\
\hline Reino Unido & 13 & 0,9 & Reino Unido & 44230,77 & 3231,4 \\
\hline Bélgica & 8 & 0,6 & Bélgica & 26065,84 & 1861,8 \\
\hline España & 7 & 0,5 & España & 25508,14 & 1822,0 \\
\hline U.R.S.S. & 5 & 0,4 & U.R.S.S. & 20919,02 & 1494,2 \\
\hline Senegal & 5 & 0,4 & Senegal & 16039,82 & 1145,7 \\
\hline Cabo Verde & 3 & 0,2 & Cabo Verde & 12003,15 & 857,4 \\
\hline Estados Unidos & 3 & 0,2 & Estados Unidos & 8637,00 & 616,9 \\
\hline Checoeslovaquia & 2 & 0,1 & Checoeslovaquia & 7331,43 & 523,7 \\
\hline Finlandia & 2 & 0,1 & Finlandia & 6087,92 & 434,9 \\
\hline Suiza & 2 & 0,1 & Suiza & 4425,99 & 316,1 \\
\hline Noruega & 2 & 0,1 & Noruega & 6303,61 & 450,3 \\
\hline Austria & 2 & 0,1 & Austria & 4818,12 & 344,2 \\
\hline Polonia & 1 & 0,1 & Polonia & 2461,78 & 175,8 \\
\hline China & 1 & 0,1 & China & 4731,00 & 337,9 \\
\hline Marruecos & 1 & 0,1 & Marruecos & 2455,94 & 175,4 \\
\hline Irlanda & 1 & 0,1 & Irlanda & 1005,43 & 71,8 \\
\hline Holanda y Suiza & 1 & 0,1 & Holanda y Suiza & 3229,17 & 230,7 \\
\hline \multirow[t]{2}{*}{$\mathrm{s} / \mathrm{d}$} & 1 & 0,1 & $\mathrm{~s} / \mathrm{d}$ & 4341,00 & 310,1 \\
\hline & 1055 & & & & \\
\hline
\end{tabular}

Fuente: Libros de entrada y salida de buques de la Prefectura Nacional en Puerto Quequén. 


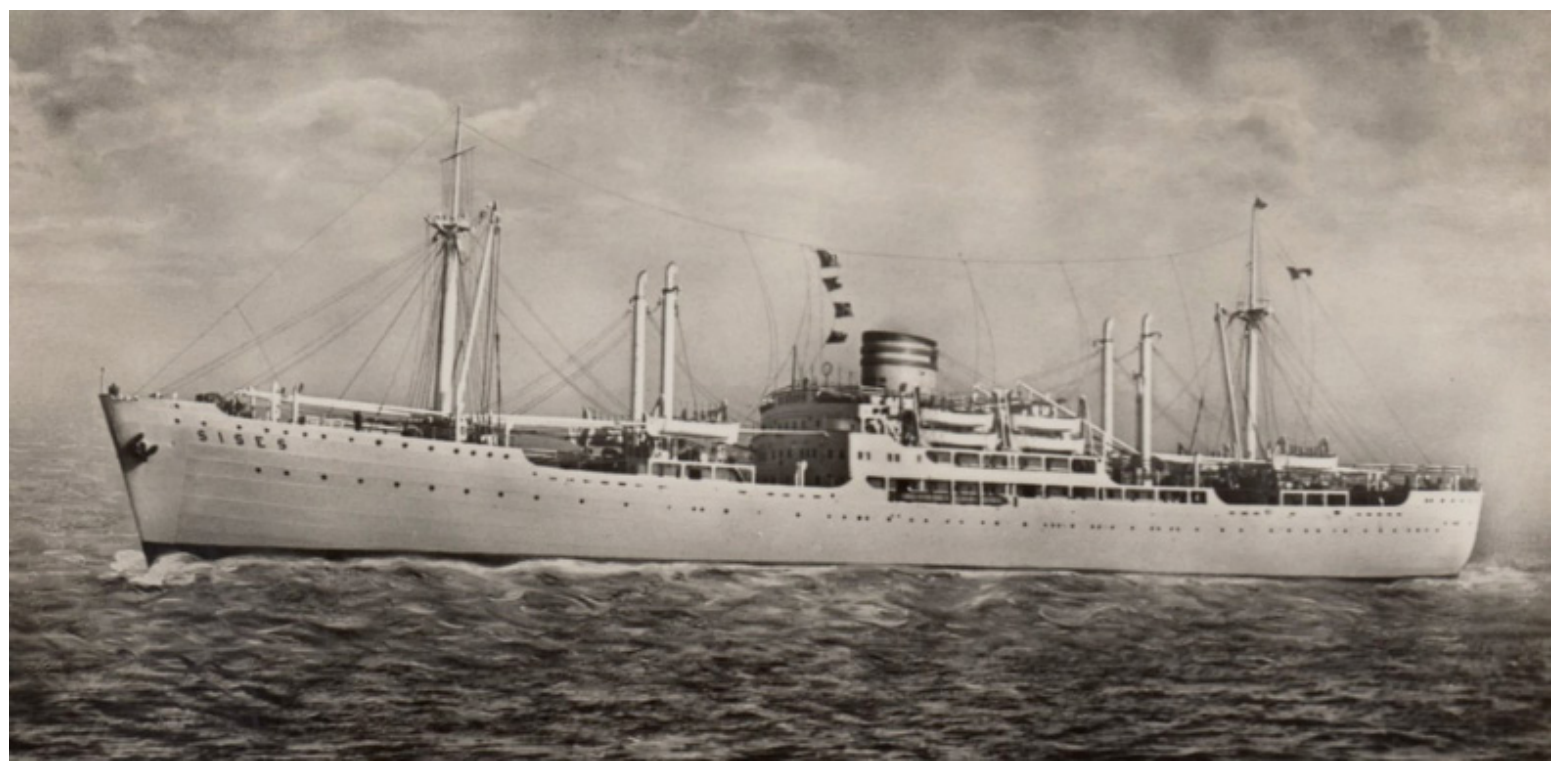

Figura 4. Buque a motor diésel italiano Sises, Puerto Quequén 1951. Fuente: Fundación Histarmar (http://www.histarmar.com.ar/)

al estatal o para estatal Companhia de Navegação Lloyd Brasileiro, creada en 1894 y desarticulada en 1997. Esa compañía incorporó numerosos buques a motor en sus naves que estaban bautizadas con nombres de países latinoamericanos.

En segundo lugar, y producto de la recuperación de las relaciones con Italia y Alemania después de la Segunda Guerra Mundial tenemos a estos destinos en los puestos segundo y cuarto respectivamente. Dos tradicionales socios comerciales de Argentina, como la República Oriental del Uruguay, los Países Bajos y Perú completan el primer conjunto con más de cien mil TRB.

Un segundo grupo que está por debajo de esta cifra y las diez mil TRB tiene a Chile, Dinamarca, Francia, Reino Unido, Bélgica, España, la ex U.R.S.S., Senegal y Cabo Verde, en ese orden. Los dos últimos destinos seguramente escalas hacia otros destinos resueltos durante el viaje. Vemos como la relación con el socio comercial más importante durante décadas, el Reino Unido, aparece muy atrás en esta compulsa. Once destinos completan el cuadro, desde Estados Unidos hasta un destino doble: Holanda y Suiza, los cuales reducen a nueve esa cifra ya que forman parte de los anteriores.

Es decir, 15 destinos europeos, 4 americanos, 1 asiático y 3 africanos que como hemos dicho son escalas hacia otros europeos. Esta información es coherente con el destino de las exportaciones (Tabla 8) argentinas en el período, sobre todo luego de 1952, donde Europa comenzó a crecer como socio comercial a expensas del resto de los países, sobre todo, americanos.

El incremento de las motonaves y del comercio exterior argentino durante la aplicación del Plan Marshal en Europa, parecen haber ido de la mano. 
Tabla 8. Tripulación media según método de propulsión y tripulante por TRB de las embarcaciones (1952-1966) ${ }^{8}$

\begin{tabular}{|c|c|c|c|c|c|c|}
\hline \multirow{2}{*}{ Año } & \multicolumn{3}{|c|}{ Tripulación media } & \multicolumn{3}{c|}{ Tripulante por TRB } \\
\cline { 2 - 7 } & Motor & Vapor & Total & Motor & Vapor & Total \\
\hline 1952 & 50,2 & 44,4 & 45,8 & 62,0 & 60,4 & 60,8 \\
\hline 1953 & 46,1 & 44,5 & 45,3 & 70,2 & 76,8 & 73,5 \\
\hline 1954 & 40,9 & 38,2 & 39,1 & 62,0 & 90,3 & 80,4 \\
\hline 1955 & 40,5 & 41,2 & 40,9 & 59,8 & 81,9 & 71,7 \\
\hline 1956 & 45,9 & 43,0 & 45,1 & 71,1 & 71,6 & 71,2 \\
\hline 1957 & 41,1 & 42,9 & 41,3 & 74,6 & 62,7 & 73,3 \\
\hline 1958 & 36,4 & 40,3 & 37,1 & 69,5 & 64,5 & 68,6 \\
\hline 1959 & 33,0 & 37,6 & 34,3 & 66,8 & 80,3 & 70,9 \\
\hline 1960 & 31,8 & 36,7 & 33,9 & 75,3 & 93,4 & 83,7 \\
\hline 1961 & 34,9 & 37,2 & 35,4 & 86,8 & 95,3 & 88,6 \\
\hline 1962 & 35,2 & 36,8 & 35,5 & 109,1 & 97,7 & 106,9 \\
\hline 1963 & 32,1 & 36,7 & 32,5 & 101,3 & 97,2 & 100,9 \\
\hline 1964 & 31,9 & 28,8 & 31,7 & 91,5 & 69,9 & 90,2 \\
\hline 1965 & 32,0 & 29,0 & 31,6 & 140,0 & 129,7 & 138,7 \\
\hline 1966 & 28,2 & 29,0 & 28,3 & 129,9 & 103,2 & 128,0 \\
\hline Promedio general & 35,3 & 38,7 & 36,2 & 88,1 & 84,0 & 87,0 \\
\hline & & & & & \\
\hline & & 356 & \\
\hline
\end{tabular}

Fuente: Orlando Ferr Fuente: Libros de entrada y salida de buques de la Prefectura Nacional en Puerto Quequén. eres, (2005).

¿Más o menos tripulantes?

Según (Gardiner \& Greenway, 1994) “La alimentación a gasoil no se empleaba generalmente en los buques de carga de la época [se refiere a antes de la Gran Guerra] y necesitaban proporcionar espacios considerables para cantidades de carbón, que con su peso, tuvieron un efecto adverso sobre las ganancias de los buques que hacían viajes prolongados." Otro elemento que considerar es la fuerza de trabajo necesaria para conducirlos. Burmeister y Wain (Licenciatarios de Rudolf Diesel) pronto fueron capaces de convencer a la East Asiatic Company de que el motor diésel podría superar estos problemas de un plumazo, así como prescindir de un gran número de fogoneros. El primero de los problemas seguramente se superaba con el diésel, el segundo es más complejo de dilucidar.

8 Los datos de 1951 no están completos por eso no se incorporó ese año, lo cual no afecta el proceso. 


\section{J. A. Mateo}

La Tabla 8 es elocuente en tanto que a medida que avanzó la transición la cantidad de tripulantes por tamaño de la embarcación se redujo. Sin embargo, a medida que se incrementaba el porte de las embarcaciones éste también crecía, es decir, la transición a los modernos buques con una docena de tripulantes no se produjo aparentemente en este momento sino más adelante en el tiempo.

\section{CONCLUSIONES}

Tradicionalmente, el auge de la etapa dorada de la agroexportación en Argentina y otros países es asociada a la "revolución en los transportes" casi como variable independiente. Esto es que la disminución de los valores en los fletes correspondía un incremento de las exportaciones agrarias con hasta entonces altos fletes por unidad de volumen (sobre todo de los derivados agrarios). La incorporación del frigorífico a las naves forma parte de esa ecuación e incluso también la inmigración internacional masiva que tuvo como destino al continente americano.

Sin desconocer la importancia de este acontecimiento hemos querido ponerlo en una medida más justa. Hemos podido comprobar que el afianzamiento de esta "revolución" fue bastante más lenta y compleja de lo supuesto. Fueron necesarios para ellos mayores progresos tecnológicos que la mera, aunque muy relevante, invención del sistema. E incluso la realización de importantísimas y extensas (en tiempo y espacio) obras de infraestructura y logística portuaria que lo complementaran (dársenas, medios de elevación, accesos, playas de maniobra, depósitos de carbón, etc.). Un elemento contemporáneo que no hemos sumado aquí fue el cable submarino de telégrafo que cerró el sistema y permitió realizar negocios en tiempo real y no depender del traslado de personas.

Fue así que velas y chimeneas y cascos metálicos y de madera convivieron en los puertos argentinos hasta principios del siglo pasado. Finalmente, la propulsión a vapor se impuso, y durante décadas "vapor" fue sinónimo de "buque" cuando comenzaban a dejar de serlo. La alerta de esta contradicción, que encontramos al contrastar fuentes (de aduana y policía portuaria) nos apareció con la flota del Lloyd Brasileiro, en tiempos en que la sociedad comercial con Argentina en tiempos del gobierno de Getulio Vargas en Brasil se incrementaba.

Mientras el vapor se hacía hegemónico, por un lado, la apertura del Canal de Panamá establecía un nuevo estándar, los gigantescos para la época buques tipo "panamax" y la industria petrolera incrementaba los ensayos, cada vez más exitosos, con el motor a explosión inventado por el francoalemán Rudolf Diesel en 1892.

Como había ocurrido en la primera transición, ambos medios de propulsión convivieron largos años. El motor fue incorporado por la armada argentina y en embarcaciones menores hasta que fueron montándose en los bulk carriers. Al ser creada la empresa YPF por parte del general ingeniero Enrique Mosconi, la industria petrolera también en Argentina dio el puntapié inicial en los motores como propulsores de las naves que acercaban el petróleo 
patagónico a los puestos bonaerenses.

Hubo que esperar no obstante hasta la segunda posguerra para que avanzara esta transición, demorada tanto por la amortización de los buques a vapor, por intereses sectoriales o por crisis petroleras.

A juzgar por los datos de Puerto Quequén esa transición se inició alrededor de 1951, donde los buques equipados con motores a explosión de las banderas más importantes en el tráfico internacional superaron por primera vez en cantidad y porte a los vapores, y quince años después el vapor finalizaba su corto, pero muy fructífero reinado de siete u ocho décadas. Los armadores más importantes (a juzgar por la aparición de numerosas "banderas de conveniencia" con este sistema) los fueron incorporando rápidamente para todas sus rutas. La velocidad y los costos sin embargo no parecen haber afectado tanto a los costos de fuerza de trabajo a bordo, al menos por el número de tripulantes.

Finalmente, este estudio se basa en un caso, Puerto Quequén, con el cual nos aproximamos a medir y evaluar el proceso de transición. Seguramente -aunque creemos que poco-, otros estudios confirmarán o refutaran este proceso.

Veleros, vapores y motores diésel convivieron en un momento. El vapor desplazó a la vela y el motor triunfó sobre ambos. Mientras tanto, la energía nuclear que parecía arrasar hace unas décadas apenas fue usufructuada por la industria militar. El 22 de mayo de 1958 comenzó en Camden (Nueva Jersey) la construcción del primer barco de propulsión nuclear para pasajeros y carga, el Savannah, que fue botado en 1960. En 1962 fue vendido a una empresa privada para su uso comercial experimental, pero resultó un fracaso financiero. Lo que sería la tercera transición en la propulsión marítima aún tiene que esperar y la navegación (y el petróleo) siguen siendo responsables de un 90\% del comercio internacional hasta este momento.

\section{REFERENCIAS}

Bowen, F. (1930). A Century of Atlantic Travel, 1830-1930. Boston: Little, Brown, and Co. Britannica, T. E. of E. (2013). Claude-François-Dorothée, marquis de Jouffroy d'Abbans. Recuperado 30 de septiembre de 2017, a partir de https://www.britannica.com/ biography/Claude-Francois-Dorothee-marquis-de-Jouffroy-dAbbans

Britannica, T. E. of E. (2018). Sir Charles Algernon Parsons (British engineer). Recuperado 22 de agosto de 2018, a partir de https://www.britannica.com/biography/CharlesAlgernon-Parsons

Cohn, R. L. (2005). The Transition from Sail to Steam in Immigration to the United States. The Journal of Economic History, 65(2), 469-495.

Corthell, E. L. (1903). Two Years in Argentine as the Consulting Engineer of National Public Works. American Geographical Society, 35(5), 439-471.

De la Fuente, D. (1883). Censo General de la Provincia de Buenos Aires. La Plata: Imprenta de El Diario. 
Ferreres, O. (2005). Dos Siglos de Economia Argentina 1810 - 2004. Buenos Aires: Norte Y Sur. Fodor, J., \& O’Connell, A. (1973). La Argentina y la economía atlántica en la primera mitad del siglo XX. Desarrollo Económico, 49, 3-65.

Gardiner, R., \& Greenway, A. (1994). The golden age of shipping: the classic merchant ship, 1900-1960. Annapolis, MD: Conway Maritime.

Giberti, H. (1985). Historia económica de la ganadería argentina. Buenos Aires: Hyspamérica. Giménez i Blasco, J. (2009). De la vela al vapor. La marina catalana a través d'una família de Vilassar de Mar: els Sust. Barcelona: Pagés Editors.

Hartenberg, R. S. (2018). Robert Fulton. American Inventor. Recuperado 22 de agosto de 2018, a partir de https://www.britannica.com/biography/Robert-Fulton-American-inventor

Konvitz, J. W. (1994). The Crises of Atlantic Port Cities 1880 to 1920. Comparative Studies in Society and History, 36, 293-318.

MAN Diesel \& Turbo. (2012). M/S Selandia 100 years. Recuperado a partir de http:// selandia100.dk/diesel

Mateo, J. (2014a). Crisis mundial e integración regional. El tráfico naviero como indicador. (Puerto Quequén, 1929-1955). Bogota.

Mateo, J. (2014b). El impacto de un nuevo puerto: la construcción de su hinterland y de su foreland. Puerto Quequén, provincia de Buenos Aires entre 1921 y 1932. Mundo Agrario, 15(29), web.

Mateo, J. (2015a). Gringos que montaban olas. Historia de la pesca costera en Argentina. Mar del Plata: GESMar.

Mateo, J. (2015b). Las banderas de conveniencia: ¿el huevo o la gallina de los paraísos fiscales? Desenvolvimento Socioeconômico em debate, 1(2), 127-1.

Mateo, J. (2015c). Oro negro del Caribe en la Bahía Blanca. El transporte naval de petróleo en el camino al autoabastecimiento en Argentina (1951-1963). memorias, (27), 207-243.

Mateo, J., \& Nogueira, J. L. (2014). Entre el viento y el humo. Embarcaciones, puertos y tripulantes en la provincia de Buenos Aires en los primeros censos nacionales (18691914). En N. Biangardi \& M. E. Sandrín (Eds.), Los Espacios portuarios.Un lugar de encuentro entre disciplinas (pp. 135-154). La Plata: UNLP-Prohistoria.

Minchinton, W. (1985). The role of the British South Atlantic islands in sea-borne commerce in the nineteenth century. En Actas del IV Coloquio de Historia Canario-americano (pp. 543-576). Las Palmas: Universidad de Las Palmas de Gran Canaria.

Silvestri, G. (2003). El color del río. Historia cultural delpaisaje del riachuelo. Bernal: Universidad Nacional de Quilmes.

Suárez Bosa, M. (1995). Economía, sociedad y relaciones laborales en Canarias: una aproximación a la situación de los trabajadores en Gran Canaria, Lanzarote y Fuerteventura. Universidad de Las Palmas de Gran Canaria, Servicio de Publicaciones.

Tolf, R. (1975). The Russian Rockefellers: the saga of the Nobel family and the Russian oil industry. Stanford: Hoover Press. Recuperado a partir de http://en.wikipedia.org/wiki/ 
Vandal_(tanker)

USCG-United States Coast Guard. (2009). The Maritime The Maritime Strategy Strategy.

Washington. Recuperado a partir de http://novanavyleague.org/CS-21 Brief (Jan 09). pdf

Valdaliso, J. M. (1992). La transición de la vela al vapor en la flota mercante española: cambio técnico y estrategia empresarial. Revista de Historia Económica, 10(1), 63-98.

Zamora Carranza, M. (2004). La frontera del frío. Sevilla: Universidad de Sevilla.

Fuentes de información

De la Fuente, D. (1872). Primero censo de la República Argentina. Buenos Aires: Imprenta del Porvenir.

De la Fuente, D. (1908). Segundo censo de la República Argentina. Buenos Aires: Taller tipográfico de la Penitenciaría Nacional.

Martínez, A. B. (1916). Tercer censo nacional. Buenos Aires: Talleres Gráficos de L. J. Grosso y Cia.

Prefectura Nacional Argentina, Libro de entrada y salida de Buques, 1914-2012 (tres tomos). Aduana de Puerto Quequén, Libro de entrada y salida de buques, 1957-1983. 
